\title{
Experimental investigation of tar arresting techniques and their evaluation for product syngas cleaning from bubbling fluidized bed gasifier
}

\author{
Irfan Ul Hai ${ }^{\mathrm{a}}$, Farooq Sher ${ }^{\mathrm{b}}$, Gul Zarren ${ }^{\mathrm{a}, \mathrm{c}}$, Hao Liu ${ }^{\mathrm{a}}$ \\ a. Faculty of Engineering, University of Nottingham, Nottingham NG7 2RD, UK \\ b. School of Mechanical, Aerospace and Automotive Engineering, Faculty of Engineering, \\ Environmental and Computing, Coventry University, Coventry CV1 2JH, UK \\ c. Department of Chemistry, Government College Women University, Faisalabad 38000, Pakistan
}

\begin{abstract}
Hazardous waste products along with the syngas produced from biomass gasification are one of the major problems of today world. Tar and other solid contaminants removal from syngas are necessary as it is widely used for the production of energy in thermal and power sectors. The raw syngas can be clean up by directly controlling the operating parameters and applying cleaning units. This study aimed to analyze bubbling fluidized bed gasifier and focuses on investigating the novel tar reducing techniques. Different cleaning units; char bed, woodchip bed and mop fan were used to arrest tar directly from producer gas. For the first time, a novel strategical technique of mop fan based on water spray was evaluated. Results showed that tar arrest with bio-char is unsuccessful due to the burning of bed while the average concentration of tar captured by woodchips and mop fan with or without water spray was $0.459 \mathrm{mg} / \mathrm{L}, 0.987 \mathrm{mg} / \mathrm{L}$ and $0.617 \mathrm{mg} / \mathrm{L}$ respectively. Furthermore, the concentration of naphthalene and phenanthrene reduced
\end{abstract}

\footnotetext{
* Corresponding author. School of Mechanical, Aerospace and Automotive Engineering, Faculty of Engineering, Environmental and Computing, Coventry University, Coventry, CV1 2JH, UK. E-mail addresses: Farooq.Sher@ coventry.ac.uk, Farooq.Sher@ gmail.com (F. Sher).
} 
significantly by $96.46 \%$ and $99.27 \%$ with water spray based mop fan. Overall tar arresting percentage efficiency with small woodchip, large woodchip, mop fan without water and mop fan with water spray was $22.5 \%<29.4 \%<60.54 \%<89.61 \%$ respectively. Hence, these investigations lead to the important findings that mop fan with water spray can be deployed directly to capture contaminants, to prevent the production of waste and to increase the efficiencies of clean syngas for the safer use in the power sector.

Keywords: Renewable energy; Biomass; Gasification; Tar contaminants; Cleaning strategies and Syngas. 


\section{Introduction}

In recent times global critical energy demands have increased very speedily. Globally, the energy consumption increases by one third over the next 25 years, according to the recent scenario of World energy outlook 2018 report (Capuano, 2018). Evolving transition scenario shows that energy consumption demand will become more than double by 2060 (Schiffer et al., 2018). In sighting the 1990s gas emission level, the European institution forecast to reduce these emissions to $80 \%$ within the next 30 years (Antenucci and Sansavini, 2019). Owing to the amassed energy demands greenhouse gas emissions become the major communal concern. To resolve these emissions, basically two scheme could be used, that is emission trading schemes and renewable support schemes (Mathur and Arya, 2019).

Global warming and greenhouse gas emissions not only urge researchers to cope with the increasing global warming situation but also encouraged the world to find a different substitute for fossil fuels like biomass, solar, nuclear and hydropower energy sources. Previously fossil fuels were used as a major source of energy (Herzog et al., 2001), face fast depletion due to its long term production time and excessive use (Allen et al., 2009). Currently, scientists focused to figure out alternative energy-producing strategies to get maximum energy (Sher et al., 2017; Sher et al., 2018). Different biomass sources could play a vital role in meeting the demands of energy and heat as this technology has many advantages, i.e. easily storable, give fewer emissions, carbon neutral (Lim, 2007), have high volatile compounds, have sustainable convertibility into carbonaceous material and have wide range of application in environmental, catalytic and electrical sectors (Yang, D.-P. et al., 2019). Biomass can be converted to fuel for heat and power 
production by two different methodologies i.e. biochemical conversions (Kumar et al., 2009) and thermochemical conversions (Azri et al., 2018).

In present days, biomass is utilized by direct combustion for power production but it is a somewhat old method and has some disadvantages such as it produces heat more than the power production by using low capacity processing lines. Instead, gasification technique has received significant heed by mitigating the severe climate changes and energy crisis (Yang et al., 2018). The major benefit of this technology is that it efficiently gives high power production (LISÝ et al., 2009) and reduce harmful gas emissions (Baláš et al., 2012). In biomass gasification, syngas contains hydrogen $\left(\mathrm{H}_{2}\right)$, carbon monoxide $(\mathrm{CO})$, carbon dioxide $\left(\mathrm{CO}_{2}\right)$, water $\left(\mathrm{H}_{2} \mathrm{O}\right)$, nitrogen $\left(\mathrm{N}_{2}\right)$, tars, char and a small amount of hydrocarbons (Moulijn et al., 2013). Feedstock dimensions, gasifying medium (Sher et al., 2018), biomass material, catalyst, sorbent, temperature and pressure of gasifier (Sher et al., 2017) depicts the quality of syngas (Kirsanovs et al., 2017).

The temperature of the gasifier is a very important factor. When air is used as a gasifying medium, the producer gas at a temperature from 750 to $1000{ }^{\circ} \mathrm{C}$ gives lower to medium calorific value due to the presence of air and nitrogen. Tar belongs to primary, secondary and tertiary class produces with a gradual increase in temperature from $200{ }^{\circ} \mathrm{C}$ to $>800{ }^{\circ} \mathrm{C}$ respectively (Benedikt et al., 2019). In syngas production, tar formation causes problems as it not only blocks valve, pipes and injectors of internal combustion engine but also requires high maintenance cost and gas cleaning cost (Chun and Song, 2019). So, after the gasification process, engineers dreadfully need to assess and remove tar to enhance the quality of gas and fuel for its effective further use as a clean energy source (McFarlan and Maffei, 2018). Tar can be removed by physical and chemical methods that include 
catalytic cracking, thermal cracking, wet scrubbing and water spray (Anis and Zainal, 2011; Chianese et al., 2015; Yang, X. et al., 2019). Wet scrubber tar removal efficacy is far much better then bio-based tar removal material (Ahlström et al., 2019). Wet packed bed scrubber having woodchips and waste cooking oil was analyzed to assess the percentage efficiency of tar removal. This system removes high molecular weight aromatic compounds of tar with $90 \%$ efficiency (Lotfi et al., 2019).

Tar eradication by water-based scrubber and cyclone separator up to $63 \%$ and $72 \%$ were reported in the literature (Awais et al., 2018). The combination of two scrubbers along with the stripper was built for OLGA (oil and gas simulator) syngas cleaning technique that works effectively by removing phenolic and heterocyclic tar compounds with $99 \%$ and 95\% efficiency (Boerrigter et al., 2005). Hybrid systems using both the oil-based wet scrubber and heat exchanger employed before the woodchip filters effectively enhance the tar capturing efficiency up to $97.5 \%$ (Thapa et al., 2017). Recently, a new study was designed to reduce the tar component in syngas. In this study, tar was eradicated by the installation of a new axial core tube. This core circulating tube was placed in the mid of the reactor to change the direction of syngas and to reduce tar components in product gas (Poowadin et al., 2018). For cleaning tar, compressors have been introduced after the precleaning systems in biomass gasification and successfully reduce tar with $83-84 \%$ efficiency (Din and Zainal, 2018).

Previously, the researchers worked to reduce contaminants by using different rig assembly with mop fan with a small amount of water. The outcomes demonstrate that all tar contaminants proficiently evacuated, while heavy aromatic hydrocarbons removed to some extent, leaving a lot 
of naphthalene in syngas (Zhang et al., 2012). Still, there is a need to work on cleaning strategies of syngas by opting various wet to dry scrubbers. Special focus must be on the reduction of heavy polycyclic aromatic hydrocarbons and industrial implementation of clean syngas. Dry bio-based cleaner systems are not yet studied in comparison to the wet scrubbers.

The present research sheds light on short rotational crops (SRC) willow gasification and cleaning strategies of product syngas. This research encompasses the qualitative as well as quantitative analyses to estimate the nature and amount of tar's contaminants in the product gas. The main focus of this research is on a range of tar removal strategies using; (i) secondary woodchip bed, (ii) secondary biochar and (iii) mop fan with and without water spray. Three series of mentioned experiments have been run by installing different units, relevant to each strategy, next to the cyclone in the gasifier. These cleaning methodologies have opted for the purification of gasifier's product gases from tar contaminants, and later on, comprehensively made a comparison between these cleaning strategies to evaluate the best system which enables to explore the best scrubbing approach. Up until now, different cleaning strategies for the use of syngas have been explored but still, there is a need to focus on novel cleaning systems and its application on an industrial level. However, applicable cleaning approaches to remove polycyclic aromatic compound have not received adequate attention especially in the conjoint effect of wet and dry based cleaning systems using low cost appropriate wet system.

\section{Experimental techniques and procedures}

The material required for gasification, experimental setup and operating conditions of gasifier used for the evaluation of tar removal were discussed. 


\subsection{Material characteristics}

Fresh short rotational crops (SRC) willow woodchips (size: 3-10 mm) from a local SRC willow grower were purchased for gasification in this study. SRC willow woodchips were examined by biomass bubbling fluidized bed gasifier (BBFBG) under controlled conditions of airflow rate, feeding rate, temperature, and pressure. The main purpose of the present work is to study the innovative gas cleaning strategies and assess tar capturing techniques. The proximate and ultimate analysis of SRC willow woodchips is given in Table 1.

\subsection{Experimental setup of biomass gasifier and tar arrest}

The experimental setup of biomass bubbling fluidized bed biomass gasifier (BBFBG) is shown in Fig. 1, consist of biomass feeding hopper, screw feeder, cyclone, gas cooling unit, fluidized bed gasification reactor, a tar capturing unit, an electrically heated combustor, an air supply/ preheating system and data gaining devices. The biomass-feeding unit by using screw auger timed stirrer to maintain a constant supply of woodchips and required feeding rate $(1920.9 \mathrm{~g} / \mathrm{h})$. The cylindricalshaped biomass feeder is used to transfer woodchips from hopper to gasifier reactor by an inverter. The stainless steel gasifier reactor; $108 \mathrm{~mm}$ diameter and $1.8 \mathrm{~m}$ height. For preheating required gasification temperature up to $700-800^{\circ} \mathrm{C}$, the reactor contains air distribution plate with $100 \mu \mathrm{m}$ pore size and $10 \mathrm{~mm}$ thickness. To continuously monitor the gasification process, a set of thermocouples and pressure sensors are fitted in the reactor (Sher et al., 2017). At ambient temperature, compressed air is used as a medium in gasification. The cyclone is fitted at the end of the gasifier reactor for the removal of the particles, which is collected in the ash pot at the bottom of the cyclone, to achieve high efficacy. Then before entering the combustor, the product gas is cooled by gas cooler and introduced into woodchip bed and mop fan cleaning unit. Efficient 
removal of gaseous containments, de-dusting of product gas and gas circulation is achieved by using centrifugal mop fan with $0.4-0.6 \mathrm{~mm}$ diameter of each fibre and $70 \mathrm{~mm}$ fibre length. Furthermore, gas cleaning efficacy and tar removal with mop fan are enhanced by water spray, efficient fibre arrangement and by increasing fibre number and diameter as large number of fibres with large surface area (diameter) provide more surface for loading extra tar components on fibre and specific arrangement of fibre gave ample passage for syngas movement to remove tar efficiently. Tar could be collected either at the end of the cyclone by an online gas analyzer or at the end of the combustor. In this study tar sample collected from the selected sampling point as shown in Fig. 2. The series of eight dreschel bottles cool down the syngas in which the first bottle directly attached to the sampling point, next three bottles condensate moisture with cold water and ice, next three bottles used to condense tar were surrounded by the dry ice and last bottle equipped with the glass wool to capture the particulates. The constant sampling flow rate of $3.0 \mathrm{~L} / \mathrm{min}$ was monitored by the mass flow control meter. At different sampling points, tar capture can be analyzed by different techniques and removed by using a dry scrubbing method and dry-wet mix scrubbing method. For dry scrubbing, next to the cyclone a woodchip bed was constructed and installed to check the woodchip bed tar capturing efficiency from biomass product gas. For drywet mix scrubbing, next to the cyclone another cleaning unit called mop fan was installed for the same purpose maintained above (Fig. 3).

\subsection{Gasifier operating conditions}

Gasification and product gas cleaning operating conditions of willow chips are summarized in Table 2. Product gas composition depends on different gasification conditions like temperature, equivalent ratio (ER), biomass feedstock type, gasifier type and composition of bed material. As a bed material, silica sand with a $212-300 \mu \mathrm{m}$ size was used and Geldart B particles presence was 
confirmed by the fluidization test at ambient temperature in bed material. The equivalence ratio (ER) of 0.319 was used to investigate the effect of product gas composition and heating value. The overall supply of constant air of $150 \mathrm{~L} / \mathrm{min}$ was achieved by the variation of combustion airflow rate that is ER. $3 \mathrm{~L} / \mathrm{min}$ amount of air at 1 atmospheric pressure and to prevent backward diffusion, $15{ }^{\circ} \mathrm{C}$ was maintained in the hopper. Particle loading and particle removal efficiency of mop fan unit was monitored by the use of TSI DustTrak. Auger motor frequency sets up to $10 \mathrm{~Hz}$ to calibrate the biomass feeding rate. The flow rate of water spray $(0.5 \mathrm{~L} / \mathrm{min})$ and mop fan rotational speed $(60 \mathrm{rpm})$ effectively assessed the particle removal efficiency of mop fan and product gas composition. At ambient temperature, particles net weight was measured by drying the particles captured through the water spray. The product gas composition analysis at the end of gasifier was assessed by off-line gas chromatography. Different particles concentrations were checked from time to time. After the product gas analysis, tar arrest by employing secondary tar removal methods were investigated. Among the secondary tar removal method, dry scrubbing methods with small woodchips of 3-10 mm, large woodchips of 10-25 mm, char bed and dry-wet scrubbing with mop fan were employed.

\section{Results and discussion}

Amount of tar present in the syngas can not only influence the working of gasifier but also cause restriction of syngas use in power engines and sectors (Rakesh and Dasappa, 2018). To effectively remove tar from syngas, woodchip bed, biochar bed and mop fan cleaning units were installed at the end of gasifiers after the cyclone (Fig. 4). These techniques were evaluated in term of its tar removal efficiency. Tar contents were measured at two points i.e. at the inlet and at the outlet in each run/filter. 


\subsection{Tar arrest by woodchips}

Woodchip and biochar bed was evaluated for the removal of tar and are discussed in detail here.

\subsubsection{Tar arrest by small woodchips}

To capture tar from product gas, as a bed material small SRC willow woodchips of size 3-10 mm were used in woodchip bed at the end of a cyclone. Low cost, easy disposal and easy accessibility of these woodchips proved to be the best selection for its use in tar arrest technique. Tar deposited on the woodchip and two product gas samples were tested at two above mentioned points (each component concentration). These woodchips effectively capture tar as shown in Fig. 5. Each component concentration at two sampling points is calculated and the difference in its concentrations is represented as the efficiency of woodchip in arresting tar components as shown in Fig. 5. Fluoranthene and Phenantherene, reduction by woodchip were observed as $44.26 \%$ and $31.58 \%$ that are considerably higher than other tar components. While tar reduction efficiency of Naphthalene and Indene was noted as $11.97 \%$ and $0.41 \%$. By arithmetic mean calculation, the average removal efficacy of tar component using small woodchips is noted as $22.5 \%$. The significant concentration of tar decreased was observed in fluoranthene and phenantherene which is mainly due to the adsorption by the woodchips and it is verified from literature (Al-Dury, 2009) as well. Likewise, Zaitan et al. in 2016 (Zaitan et al., 2016) reported the similar results of components and acquired the best affinity of methanol, toluene and benzaldehyde for adsorption on clay.

\subsubsection{Tar arrest by large woodchips}

Tar capture from product gas was also investigated by using large woodchips of size 10-25 mm as bed material. Tar's contaminants capturing by large wood chips was carried out to identify the 
role of surface area in the adsorption process. The concentration of each component of tar was evaluated before entering and after leaving woodchip bed filter by using large size woodchip bed and the results are shown in Fig. 7.

Fluoranthene and Indene capture efficiency by large woodchips was observed as $55.35 \%$ and 63.93\% respectively that are considerably higher than the rest of the tar component. Naphthalene capture efficiency was noted as $39.59 \%$. Tar components concentration efficiently decrease as components concentration at the inlet and outlet of woodchips bed compared. By arithmetic mean calculation, the average removal efficacy of tar component by using large woodchips is noted as $29.4 \%$ that is quite higher than that of tar reduction efficiency with small woodchip bed. Tar reduction with large woodchip bed is also attributed to its adsorption affinity. Woodchip bed after the one hour of its application, adsorb tar and lower the tar content in the product gas. In comparison with the synthetic porous cordierite $(0.0128 \mathrm{~g} / \mathrm{g}$ absorbent $)$ and activated carbon $(0.0975 \mathrm{~g} / \mathrm{g}$ adsorbent $)$, tar adsorption by the woodchips bed $(0.1557 \mathrm{~g} / \mathrm{g}$ adsorbent $)$ was also reported greater in the literature (Phuphuakrat et al., 2010). Therefore, tar removal from product syngas by woodchips scrubbing proved to be more suitable because they are replicable, low cost and available in abundance.

\subsubsection{Comparison of small and large woodchips bed efficiency}

In Fig. 8, the efficiency of small and large woodchip bed for tar arrest is compared. The average tar arrest with large woodchip bed (10-25 mm) was $29.4 \%$ and with small woodchip bed (3-10 $\mathrm{mm}$ ) is $22.5 \%$. Thapa et al. (Thapa et al., 2017) reported the comparable results as $10 \%$ tar reduce by the use of corn woodchips shavings of size up to $2 \mathrm{~mm}$, while the wood shavings in combination with oil bubbler reduce tar with high efficiency. The hydrophilic nature of woodchip bed causes 
the accumulation of product gas at the surface of woodchips causing the water-soluble tar to capture at the surface of the filter bed. The more exposed bulk surface area provided extra passage to the contaminated syngas and finally, extra tar diminishes viably. Also, the large surface area of woodchip does not pile up compactly as compared to small woodchips and give enough time to pass syngas and arrest tar effectively. Therefore, the results show more efficient tar arrest with large woodchip bed from the produced syngas because of large size of woodchip and bulk mass availability. The large size woodchip is able to expose more surface area contact with product gas and capture tar more efficiently, while the small size woodchip has small surface area and forms compactly packed bed due to which show low concentration values and less tar reduction efficiency.

\subsubsection{Biochar bed}

Tar reduction from product gas sample by biochar bed was tested. Organic-based carbon material such as biochar has been vastly studied for capturing tar from syngas, as it is cheap, easily available and easy to install. In comparison to woody material, biochar gives a more porous surface to arrest tar, so, it is believed to be more effectual in tar reduction. In this study, tar reduction with the help of biochar was evidenced to be unsuccessful technique due to the complete burning of biochar in bed as shown in Fig. 9. The burning of biochar initiates when the hot product gas passed through it. Due to the passage of hot syngas, the unreacted carbon atoms in biochar starts to ignite and cause the failure of this system. In literature, Shen in 2016 (Shen, 2015) reported the successful tar reduction with biochar but also narrate that biochar has less tar absorbing ability then activated carbon with high porosity, while Nakmura et al. in 2016 (Nakamura et al., 2016) used char as tar scrubber and reported $81 \%$ tar reduction. 


\subsection{Tar arrest by Mop fan unit}

Tar removal techniques based on mop fan with or without water spray were evaluated and described here.

\subsubsection{Mop fan tar arrest without water spray}

Mop fan cleaning unit is a multifunctional device having numbers of fibre which is not only used for circulating the syngas but also for cleaning gas streams and removing gaseous contaminants. Mop fan cools down and circulates the syngas and capture tar by loading contaminants on mop fibres. The tar entrapped on the surface of mop fibres separated and clean syngas then passes through the mop fan and collected for further utilization. Through mop fan cleaning unit, the efficiency of tar reduction and other particle was investigated. Tar components were sampled before mop fan and after the mop fan cleaning unit. Individual tar component concentrations and mop fan effectiveness were analyzed as shown in Fig. 9. Mop fan for this experiment was run at $60 \mathrm{rpm}$. Phenanthrene reduced by $95.72 \%$ which was the highest reduced concentration found in tar reduction via mop fan without water spray, whereas the other components showed less change. Phenanthrene obviously reduced majorly due to the heavier component of tar. Indene and Biphenyl reduced only by $7.41 \%$ and $20.24 \%$ respectively. Average tar reduction efficiency with mop fan without water spray was noted $60.54 \%$ that is much higher than small and large woodchip bed.

\subsubsection{Mop fan tar arrest with water spray}

Syngas cleaning by the use of water spray based mop fan significantly remove tar components. This technique can prove to be potentially advantageous due to decreased cost of wastewater treatment and increased tar removal efficiency over the other liquid-based scrubbers. Mop fibres capture tar more efficiently when a small amount of water sprayed through it. The conjoint effect 
of mop fibres and water droplets enable more effective tar particulates removal. To find tar reduction, a measured amount of water $(0.5 \mathrm{~L} / \mathrm{min})$ was sprayed over the stream of gas together with the rotting mop fan. Mostly tar components solubility in water is low. Heterocyclic compounds eliminated by pure water absorption and two or three ring polycyclic hydrocarbons remain in gas and their concentrations subsequently condense. The separate liquid phase, in the form of an aerosol either leaves with gas or compelled by water. Tar assumed to be partially saturated with water supplied. Therefore, tar scrubbing is based on aerosol elimination. Disadvantages of water-based gas scrubbing are; the heat transfer into the production of low potential environment unfriendly wastewater and required cool water source and equipment. Chiller, sprinkle cooler and spray towers may utilize during summer but chiller is an expensive method while water spray usage in scrubbing is relatively cheap (Balas et al., 2014).

Individual tar components concentrations in product syngas before and after scrubbing with waterbased mop fan have shown in Fig. 11. Higher reduction of tar components is achieved with spray and mop fan filter together. In comparison to other tar components, stable polycyclic aromatic hydrocarbons like naphthalene, acenaphthalene and phenanthrene reduce majorly which is due to its affinity with unreacted carbon materials and char as reported in the literature (Guo et al., 2017). The other reason for high tar reduction by water-based mop fan is the adhering ability of water caused by the surface tension of water droplets. Percentage efficiency in tar reduction for most of tar components can be seen up to $95 \%$ which is in agreement with the results found in literature, as, Rabou et al. (Rabou et al., 2009) analyzed water scrubbing with water-based tar reduction method and noted an effective reduction of tar from $8 \mathrm{~g} / \mathrm{Nm}^{3}$ to $4.5 \mathrm{~g} / \mathrm{Nm}^{3}$. The average tar reduction efficiency with water spray based mop fan was noted as $89.61 \%$ that is evidently higher 
than all other strategies applied for tar arresting. The higher contaminants capturing efficiency of mop fan with water spray might be due to the scrubbing of tar component with the blades of mop fan and water. Tar contents from the gas stream interact with the water droplets were suspended in the stream. The surface tension of water droplet holds the tar contaminants and later on accumulates at the mop fan drainage section.

\subsubsection{Efficiency comparison of tar arrest of mop fan with or without water spray}

The efficiency of mop fan tar arrest with or without water spray is shown in Fig. 11. Other than 11'-Binaphthalene and biphenyl, mop fan was consistently captured tar particles from product syngas. It is assumed that 1-1 -Binaphthalene and biphenyl from mop fan surface blown away during sampling at exit point due to the insolubility of these two in water which causes a high concentration of 1-1-Binaphthalene and biphenyl in product gas and low efficacy of mop fan in these tar component reduction. Among the result represented in Fig. 11, mop fan running at 60 rpm with water spray of $0.5 \mathrm{~L} / \mathrm{min}$ noted as a more efficient technique to arrest tar components from product syngas. The results are in agreement with the literature as mop fan with water spray could increase efficiency from 30 to $70 \%$ for tar arrest while without water spray tar component particle capture was only around 30\% (Riffat et al., 1995). Nakamura et al. (Nakamura et al., 2016) also reported the combined effect of char scrubber and bio-oil and the results of this study shows tar reduction up to $98.0 \%$.

After discussing the major findings of this study, here the comparison of theoretical and practical implications of three cleaner techniques are presented. In order to improve clarity and enhance understanding, the summary of the major outcomes is described below. Total tar arrest in three different strategies depicted results are shown in Fig. 13. Comprehensive results of these three 
strategies show that tar reduction by a novel technique of mop fan with water spray is $0.987 \mathrm{mg} / \mathrm{L}$ as compared to woodchip and mop fan without water spray which arrest tar $0.459 \mathrm{mg} / \mathrm{L}$ and 0.617 $\mathrm{mg} / \mathrm{L}$ respectively. Mop fan with water spray reduces tar with high efficiency due to suspended water droplets. Hence, mop fan with water spray as a cleaner unit can practically be implemented in gasifiers to remove hazardous waste and contaminants.

\section{Conclusions}

The cleaner production $(\mathrm{CP})$ technologies enable us to use the product gas more efficiently for energy production. This study aims to espouse clean technology for the production of syngas with improved environmental quality and lessen the level of contaminants. Tars are the major contaminants produced during the gasification process. Herein, tar arrest overall performance for woodchips feedstock was analyzed by three different clean technologies and the conclusions are as follow:

- Among three cleaner techniques, tar capture by biochar bed do not provide successful tar arrest due to ignition and burning of secondary bed. It was observed that tar component arrest with water spray based mop fan unit is $0.987 \mathrm{mg} / \mathrm{L}$ in comparison to tar removal by woodchip $(0.459 \mathrm{mg} / \mathrm{L})$ and by mop fan unit without water spray $(0.617 \mathrm{mg} / \mathrm{L})$. Tar content percentage reduction was $29 \%$ for large woodchip bed, $60 \%$ for mop fan without water spray and $89.61 \%$ for mop fan with water spray. The higher efficiency of tar arrest for mop fan with water spray was due to the combined effect of water and fan, as extra cleaning system was provided by suspended water particles in the cleaning unit.

- These results recommend that the most efficient method for tar arrest is the usage of mop fan with water spray but the only shortcoming of this strategy is the production of wastewater which requires additional cost for its disposal. In future, to achieve energy 
demands of the world, biomass gasification systems equipped with mop fan cleaning units having water control cell could prove to be worth evaluating.

- The cleaning strategy studied here is of prime interest because in near future coal-based power plants will be replaced with the biomass based energy plants. Therefore, the strategies opted here for contaminants removal are much needed to make the environment waste-free and sustainable. Gasifier performance together with the different cleaning units effectively remove tar and the product gas could be used to run the engine as the quality of syngas achieves the running requirement of engine gas. 


\section{References}

Ahlström, J.M., Alamia, A., Larsson, A., Breitholtz, C., Harvey, S., Thunman, H., 2019. Bark as feedstock for dual fluidized bed gasifiers-Operability, efficiency, and economics. International Journal of Energy Research.

Al-Dury, S., 2009. Removal of tar in biomass gasification process using carbon materials. Chem Eng Trans 18, 665.

Allen, M.R., Frame, D.J., Huntingford, C., Jones, C.D., Lowe, J.A., Meinshausen, M., Meinshausen, N., 2009. Warming caused by cumulative carbon emissions towards the trillionth tonne. Nature 458(7242), 1163-1166.

Anis, S., Zainal, Z., 2011. Tar reduction in biomass producer gas via mechanical, catalytic and thermal methods: A review. Renewable and sustainable energy reviews 15(5), 2355-2377.

Antenucci, A., Sansavini, G., 2019. Extensive CO2 recycling in power systems via Power-to-Gas and network storage. Renewable and Sustainable Energy Reviews 100, 33-43.

Awais, M., Li, W., Arshad, A., Haydar, Z., Yaqoob, N., Hussain, S., 2018. Evaluating removal of tar contents in syngas produced from downdraft biomass gasification system. International journal of green energy 15(12), 724-731.

Azri, Y.M., Tou, I., Sadi, M., Benhabyles, L., 2018. Bioelectricity generation from three ornamental plants: Chlorophytum comosum, Chasmanthe floribunda and Papyrus diffusus. International journal of green energy 15(4), 254-263.

Balas, M., Lisy, M., Skala, Z., Pospisil, J., 2014. Wet scrubber for cleaning of syngas from biomass gasification. Development and Chemistry, Advances in Environmental Sciences, 195-201.

Baláš, M., Lisý, M., Štelcl, O., 2012. The effect of temperature on the gasification process. Acta Polytechnica 52(4).

Benedikt, F., Kuba, M., Schmid, J.C., Müller, S., Hofbauer, H., 2019. Assessment of correlations between tar and product gas composition in dual fluidized bed steam gasification for online tar prediction. Applied Energy 238, 1138-1149.

Boerrigter, H., van Paasen, S., Bergman, P., Könemann, J.-W., Emmen, R., 2005. Tar removal from biomass product gas; development and optimisation of the OLGA tar removal technology, Proceedings of the 14th European Biomass Conference \& Exhibition.

Capuano, L., 2018. International energy outlook 2018 (IEO2018). US Energy Information Administration (EIA): Washington, DC, USA 2018, 21.

Chianese, S., Loipersböck, J., Malits, M., Rauch, R., Hofbauer, H., Molino, A., Musmarra, D., 2015. Hydrogen from the high temperature water gas shift reaction with an industrial Fe/Cr catalyst using biomass gasification tar rich synthesis gas. Fuel processing technology 132, 39-48.

Chun, Y.N., Song, H.G., 2019. Microwave-induced cracking and reforming of benzene on activated carbon. Chemical Engineering and Processing-Process Intensification 135, 148-155.

Din, Z.U., Zainal, Z., 2018. Tar reduction mechanism via compression of producer gas. Journal of cleaner production $184,1-11$.

Guo, W., Ai, Y., Men, B., Wang, S., 2017. Adsorption of phenanthrene and pyrene by biochar produced from the excess sludge: experimental studies and theoretical analysis. International Journal of Environmental Science and Technology 14(9), 1889-1896.

Herzog, A.V., Lipman, T.E., Edwards, J.L., Kammen, D.M., 2001. Renewable energy: a viable choice. Environment: Science and Policy for Sustainable Development 43(10), 8-20.

Kirsanovs, V., Blumberga, D., Karklina, K., Veidenbergs, I., Rochas, C., Vigants, E., Vigants, G., 2017. Biomass gasification for district heating. Energy Procedia 113, 217-223. 
Kumar, A., Eskridge, K., Jones, D.D., Hanna, M.A., 2009. Steam-air fluidized bed gasification of distillers grains: effects of steam to biomass ratio, equivalence ratio and gasification temperature. Bioresource Technology 100(6), 2062-2068.

Lim, M.T., 2007. Characterization Of A Bubbling Fluidized Bed Biomass Gasifier. USM.

LISÝ, M., BALÁS̆, M., MOSKALÍK, J., POSPÍŠIL, J., 2009. Research into biomass and waste gasification in atmospheric fluidized bed, Proceedings of the 3rd WSEAS International Conference on Energy Planning, Energy Saving, Environmental Education, EPESE. pp. 363-368. Lotfi, S., Ma, W., Austin, K., Kumar, A., 2019. A wet packed-bed scrubber for removing tar from biomass producer gas. Fuel Processing Technology 193, 197-203.

Mathur, S.P., Arya, A., 2019. Impact of Emission Trading on Optimal Bidding of Price Takers in a Competitive Energy Market, Harmony Search and Nature Inspired Optimization Algorithms. Springer, pp. 171-180.

McFarlan, A., Maffei, N., 2018. Assessing tar removal in biomass gasification by steam reforming over a commercial automotive catalyst. Fuel 233, 291-298.

Moulijn, J.A., Makkee, M., Van Diepen, A.E., 2013. Chemical process technology. John Wiley \& Sons.

Nakamura, S., Kitano, S., Yoshikawa, K., 2016. Biomass gasification process with the tar removal technologies utilizing bio-oil scrubber and char bed. Applied energy 170, 186-192.

Phuphuakrat, T., Namioka, T., Yoshikawa, K., 2010. Tar removal from biomass pyrolysis gas in two-step function of decomposition and adsorption. Applied Energy 87(7), 2203-2211.

Poowadin, T., Polsongkram, M., Khantikomol, P., 2018. Possibility study of gasifier with axial circulating flue gas for reducing Tar, IOP Conference Series: Materials Science and Engineering. IOP Publishing, p. 012062.

Rabou, L.P., Zwart, R.W., Vreugdenhil, B.J., Bos, L., 2009. Tar in biomass producer gas, the Energy research Centre of the Netherlands (ECN) experience: an enduring challenge. Energy \& Fuels 23(12), 6189-6198.

Rakesh, N., Dasappa, S., 2018. Analysis of tar obtained from hydrogen-rich syngas generated from a fixed bed downdraft biomass gasification system. Energy Conversion and Management 167, 134-146.

Riffat, S., Shao, L., Clarke, R., Ramshaw, C., 1995. Mop fan for livestock buildings. Journal of agricultural engineering research 61(3), 191-195.

Schiffer, H.-W., Kober, T., Panos, E., 2018. World Energy Council's Global Energy Scenarios to 2060. Zeitschrift für Energiewirtschaft 42(2), 91-102.

Shen, Y., 2015. Chars as carbonaceous adsorbents/catalysts for tar elimination during biomass pyrolysis or gasification. Renewable and Sustainable Energy Reviews 43, 281-295.

Sher, F., Pans, M.A., Afilaka, D.T., Sun, C., Liu, H., 2017. Experimental investigation of woody and non-woody biomass combustion in a bubbling fluidised bed combustor focusing on gaseous emissions and temperature profiles. Energy 141, 2069-2080.

Sher, F., Pans, M.A., Sun, C., Snape, C., Liu, H., 2018. Oxy-fuel combustion study of biomass fuels in a $20 \mathrm{kWth}$ fluidized bed combustor. Fuel 215, 778-786.

Thapa, S., Bhoi, P., Kumar, A., Huhnke, R., 2017. Effects of syngas cooling and biomass filter medium on tar removal. Energies 10(3), 349.

Yang, D.-P., Li, Z., Liu, M., Zhang, X., Chen, Y., Xue, H., Ye, E., Luque, R., 2019. BiomassDerived Carbonaceous Materials: Recent Progress in Synthetic Approaches, Advantages, and Applications. ACS Sustainable Chemistry \& Engineering 7(5), 4564-4585. 
Yang, Q., Zhou, H., Zhang, X., Nielsen, C.P., Li, J., Lu, X., Yanga, H., Chen, H., 2018. Hybrid life-cycle assessment for energy consumption and greenhouse gas emissions of a typical biomass gasification power plant in China. Journal of cleaner production 205, 661-671.

Yang, X., Liu, X., Guo, T., Liu, C., 2019. Effects of Cu and Fe Additives on Low-Temperature Catalytic Steam Reforming of Toluene Over Ni/AC Catalysts. Catalysis Surveys from Asia, 1-10. Zaitan, H., Mohamed, E.F., Valdés, H., Nawdali, M., Rafqah, S., Manero, M.-H., 2016. Toluene, Methanol and Benzaldehyde removal from gas streams by adsorption onto natural clay and faujasite-Y type Zeolite. Acta Chimica Slovenica 63(4), 798-808.

Zhang, W., Liu, H., Ul Hai, I., Neubauer, Y., Schröder, P., Oldenburg, H., Seilkopf, A., Kölling, A., 2012. Gas cleaning strategies for biomass gasification product gas. International Journal of Low-Carbon Technologies 7(2), 69-74. 


\section{List of Tables}

Table 1. Ultimate and proximate analysis of SRC willow woodchip biomass.

\begin{tabular}{cc}
\hline Component & Weight (\%) \\
\hline Ultimate analysis & 5.7 \\
Hydrogen & 0.8 \\
Nitrogen & 0.1 \\
Sulphur & 37.5 \\
Oxygen ${ }^{\text {a }}$ & 45.4 \\
Carbon & 10.0 \\
Moisture & 0.5 \\
Ash & \\
Proximate analysis & 12.90 \\
Fixed carbon & 2.95 \\
Moisture & 1.26 \\
Ash & 85.84 \\
Volatiles & \\
\hline
\end{tabular}

${ }^{a}$ Calculated by the difference. 
Table 2. Operating conditions of biomass bubbling fluidized bed gasifier.

\begin{tabular}{|c|c|c|c|}
\hline Equivalent Ratio (ER) & & 0.319 & \\
\hline Biomass feeding rate $(\mathrm{g} / \mathrm{h})$ & & 1920.9 & \\
\hline Gasification air flow rate $(\mathrm{L} / \mathrm{m})$ & & 65 & \\
\hline Combustion air flow rate $(\mathrm{L} / \mathrm{m})$ & & 150 & \\
\hline Hopper air flow rate (L/m) & & 3 & \\
\hline \multirow[t]{2}{*}{ Heater temperature setup $\left({ }^{\circ} \mathrm{C}\right)$} & Upper Heater & Lower Heater & Combustor \\
\hline & 660 & 800 & 850 \\
\hline Screw feeder motor frequency (rpm) & & 20 & \\
\hline Mop fan motor frequency (rpm) & & 60 & \\
\hline Mop fan spray water flow rate $(\mathrm{L} / \mathrm{m})$ & & 0.5 & \\
\hline
\end{tabular}




\section{List of Figures}

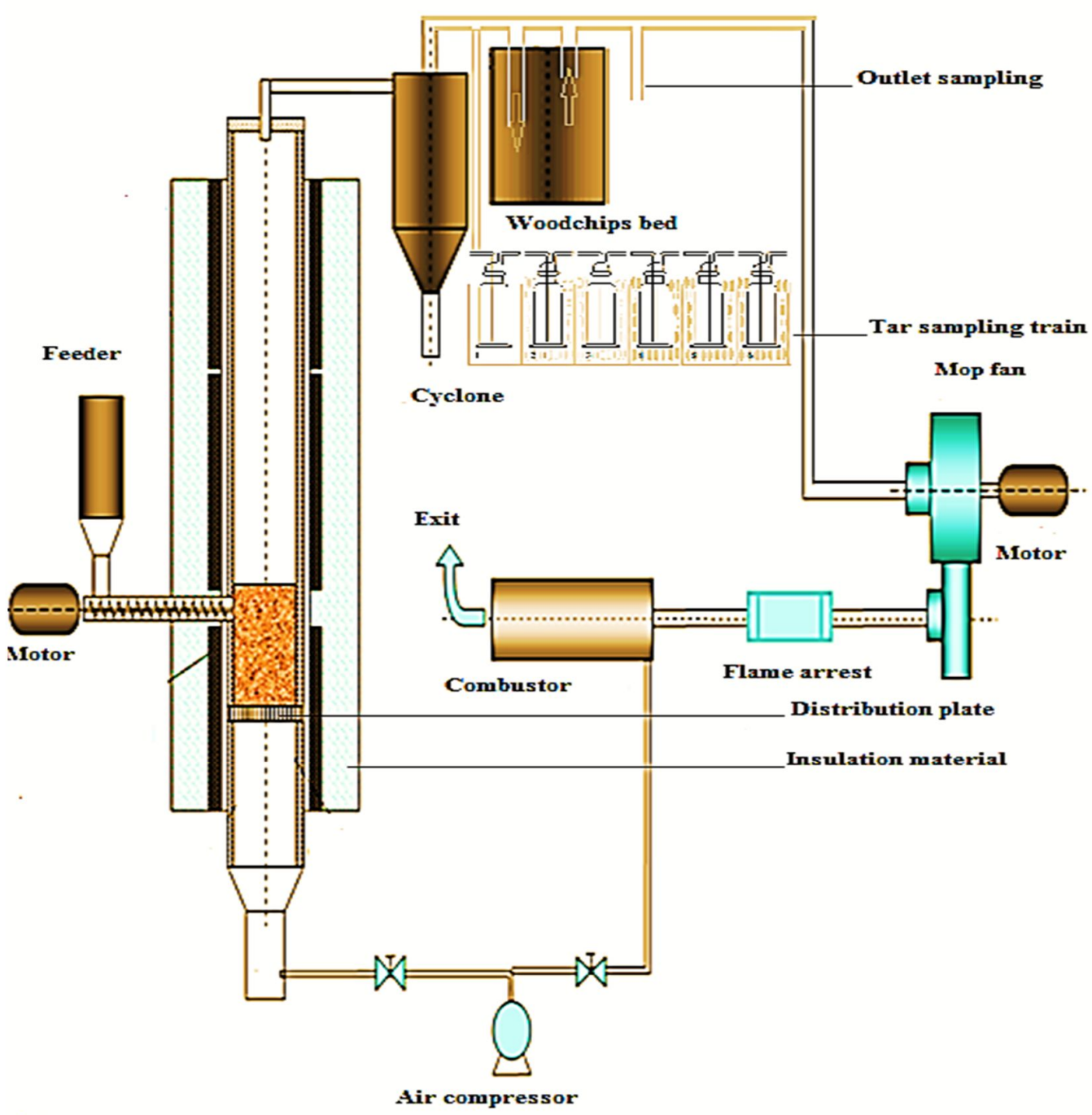

Fig. 1. Schematic diagram of biomass bubbling fluidized bed (BBFBG) gasifier experimental system. 


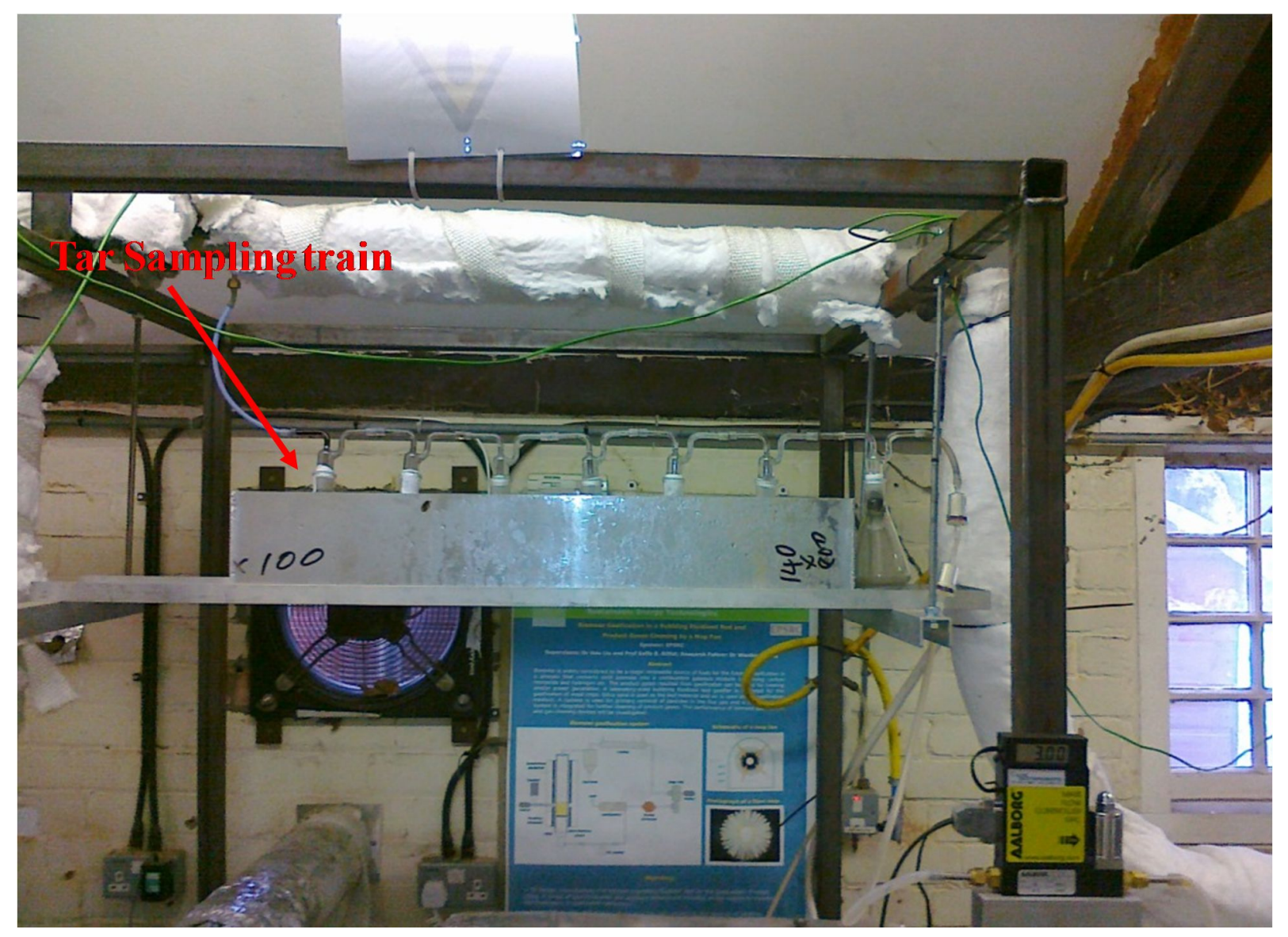

Fig. 2. Experimental setup of tar sampling train. 


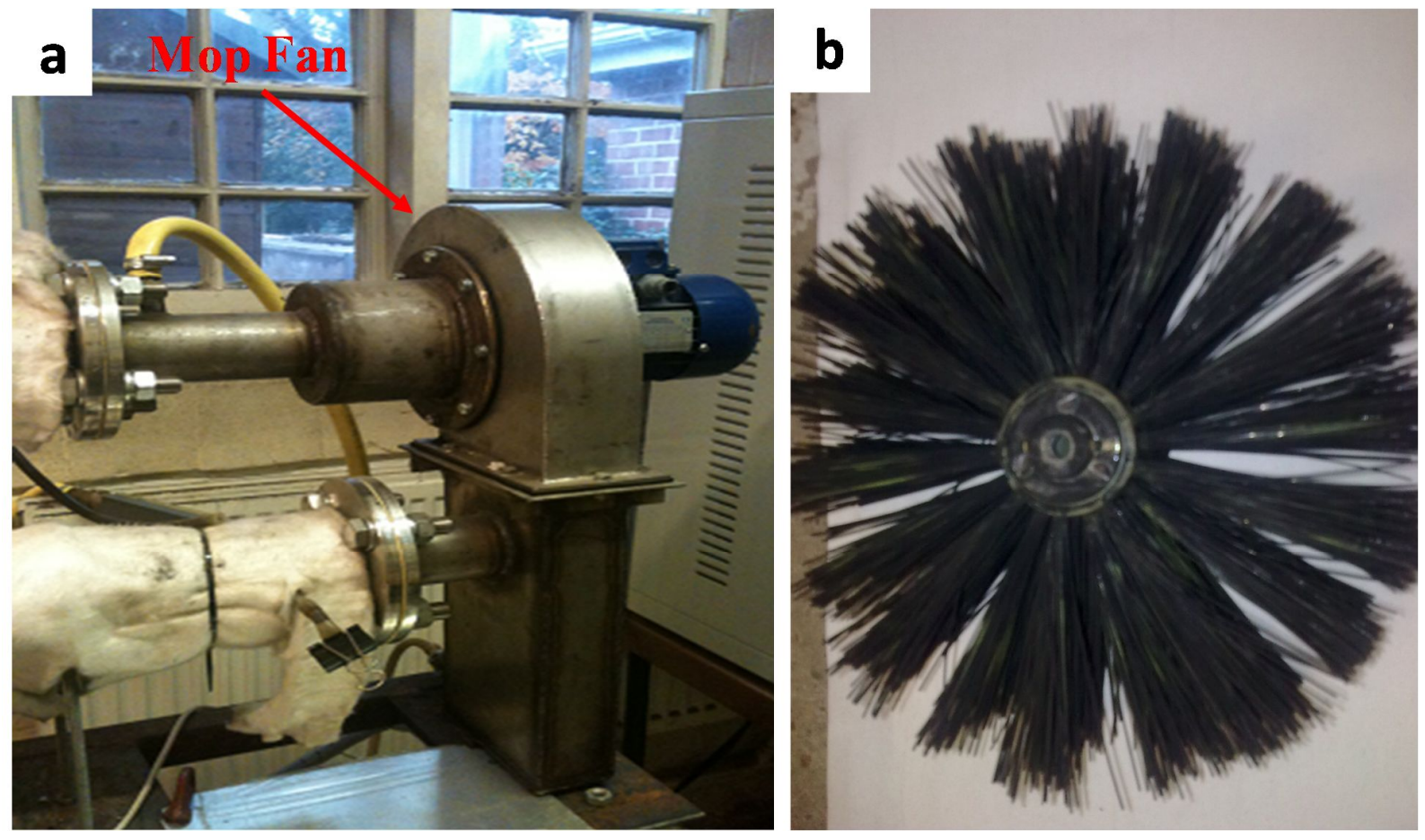

Fig. 3. Mop fan; (a) Installation next to the cyclone, (b) Real mop fan with fibres. 


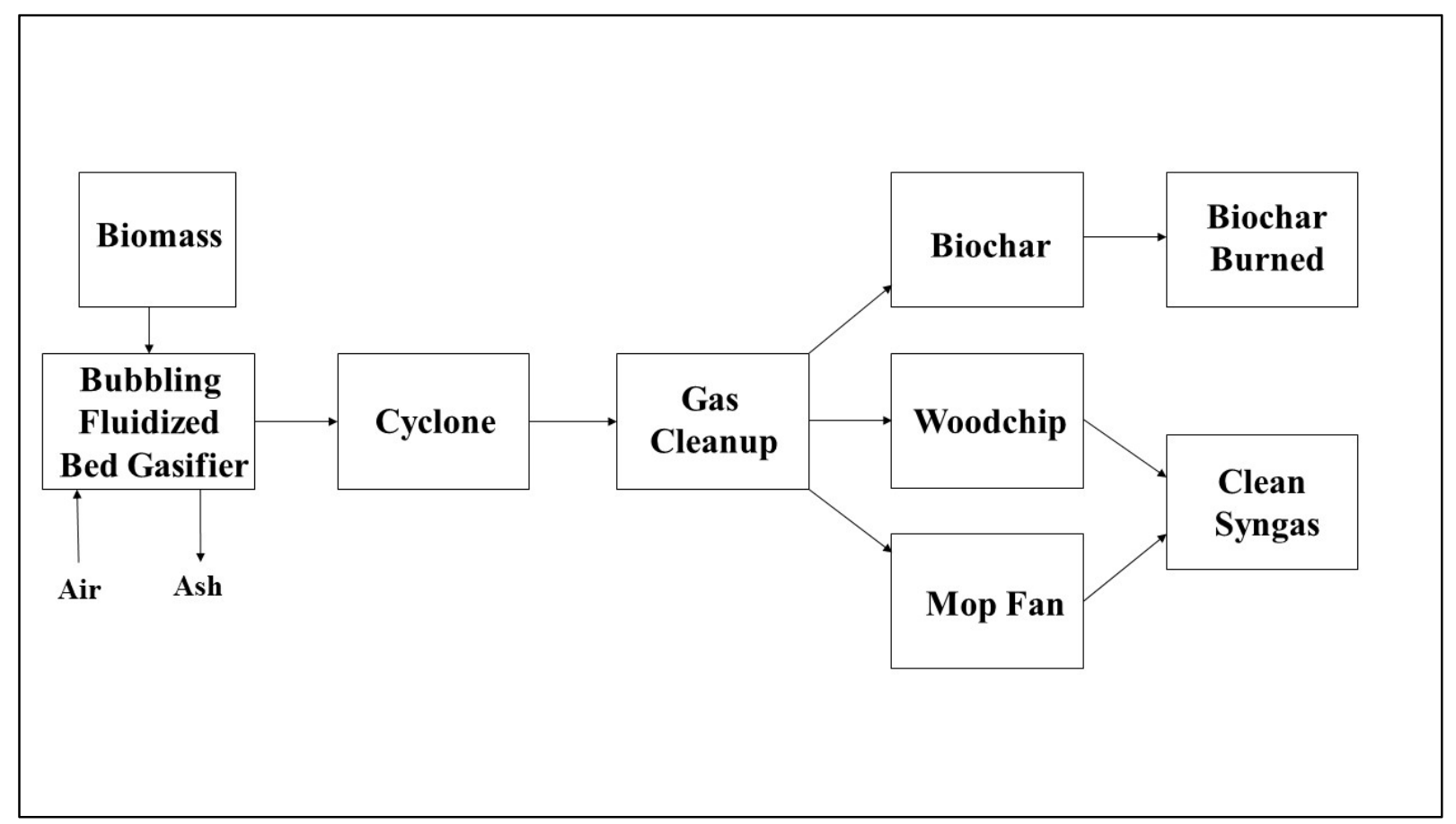

Fig. 4. Process flow diagram of the gasification process and tar arresting techniques. 

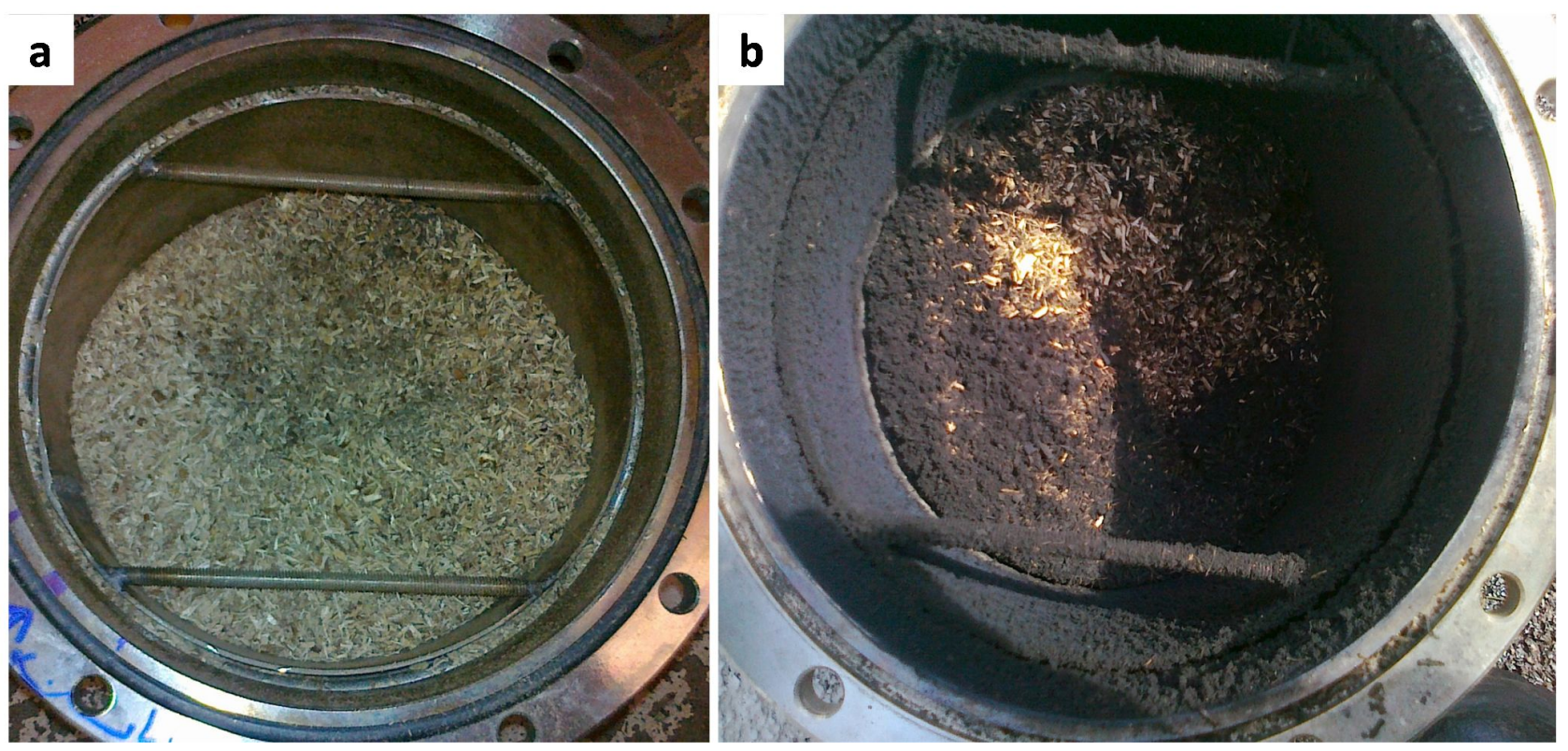

Fig. 5. (a) Woodchip bed used for the dry scrubbing, (b) tar trapped by small woodchips (3-10 $\mathrm{mm})$. 


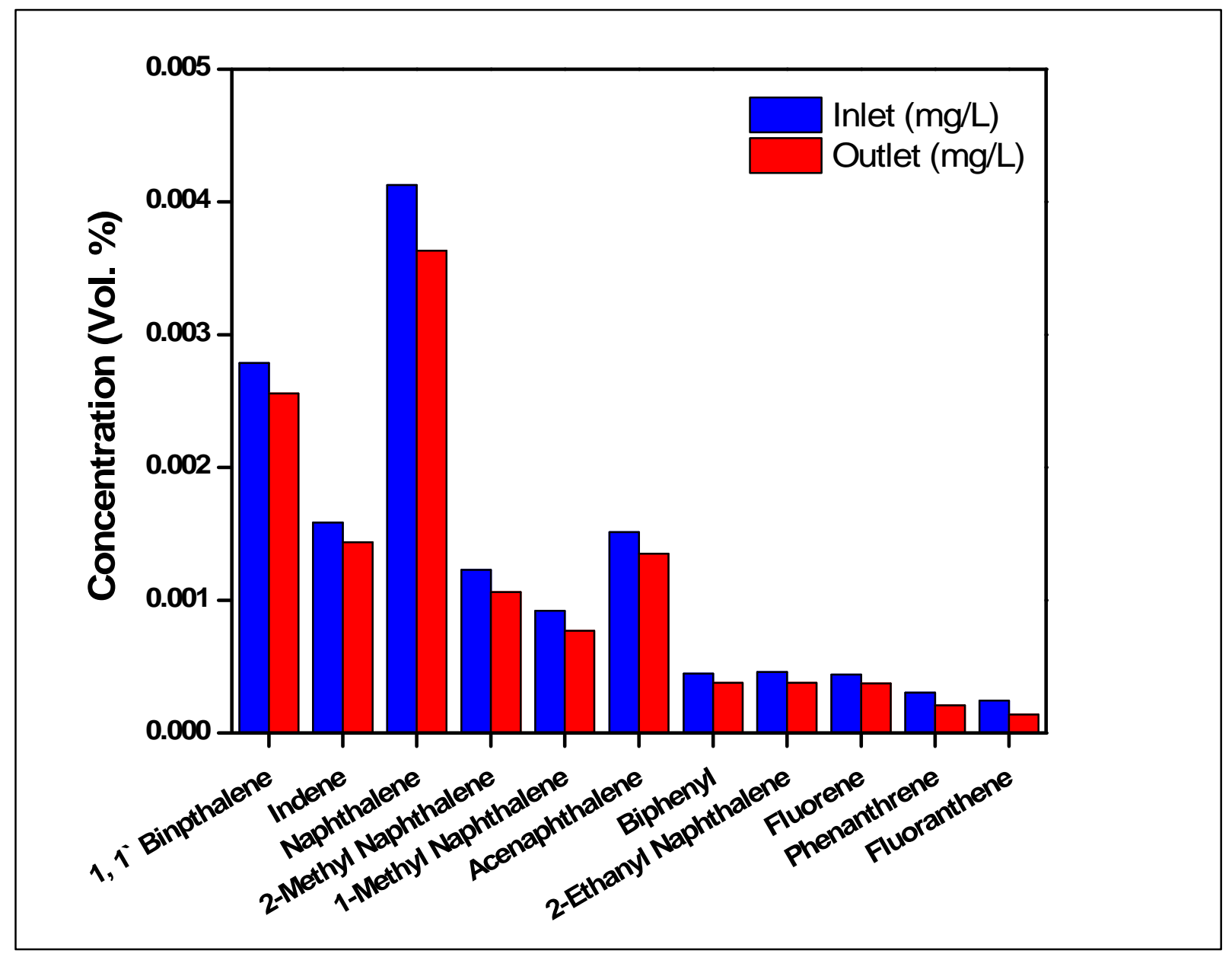

Fig. 6. Tar content concentration comparison at inlet and outlet with small woodchips bed at $1926.9 \mathrm{~g} / \mathrm{h}$ biomass feeding. 


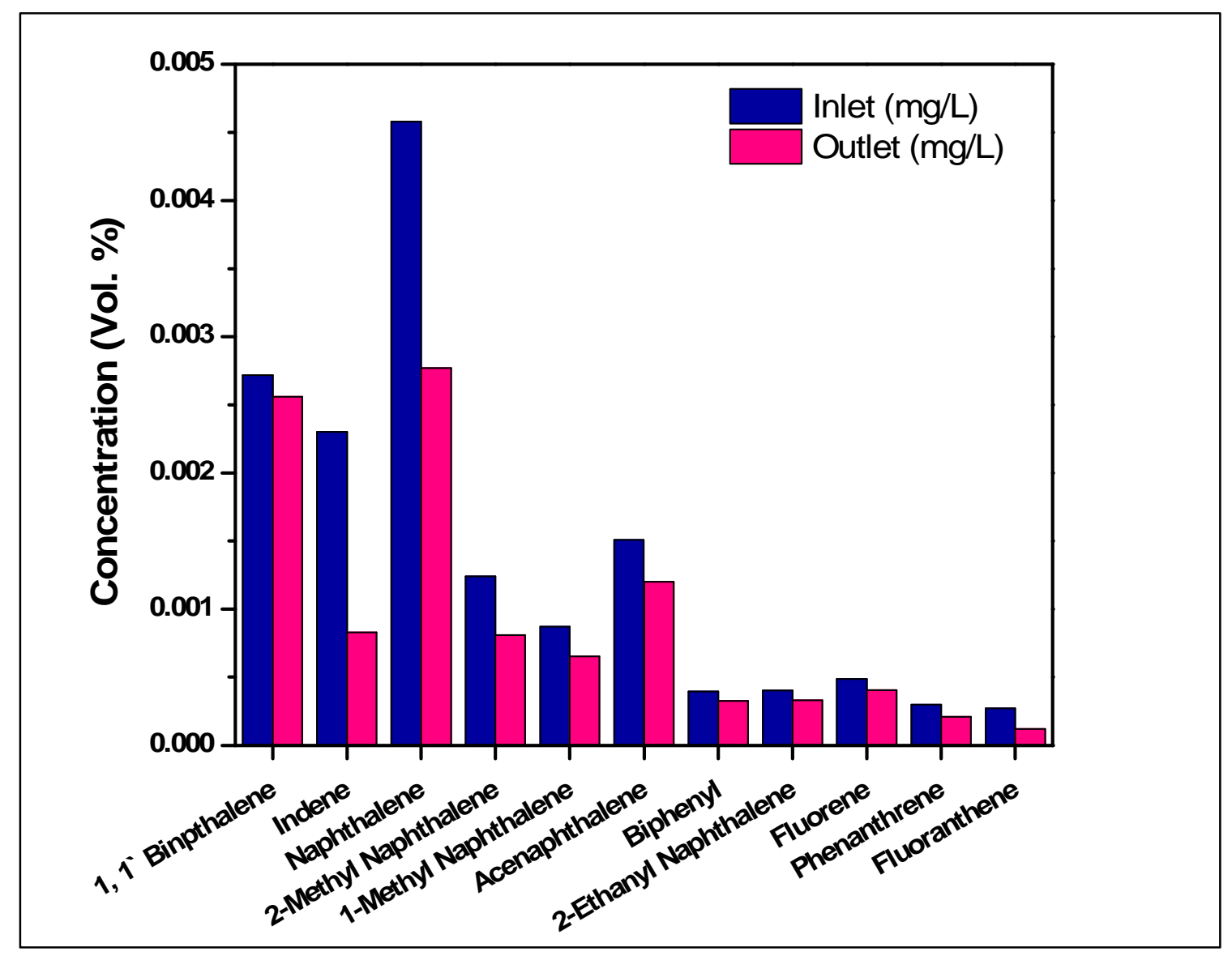

Fig. 7. Tar content concentration comparison at inlet and outlet with large woodchips bed at 1926.9 $\mathrm{g} / \mathrm{h}$ biomass feeding. 


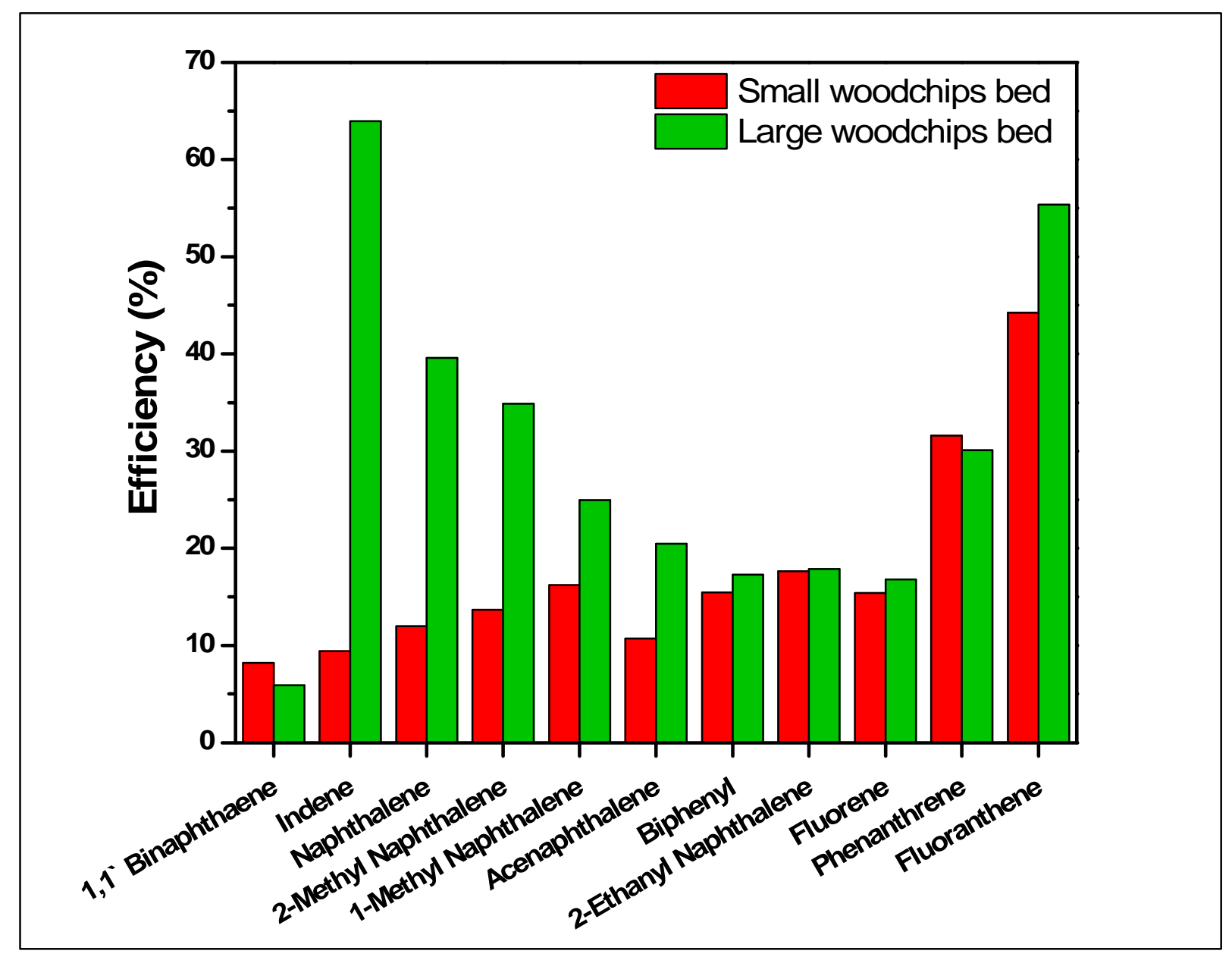

Fig. 8. Comparison of Small woodchip bed (3-10 mm) and large woodchip bed (10-25 mm) tar component capture efficiency. 


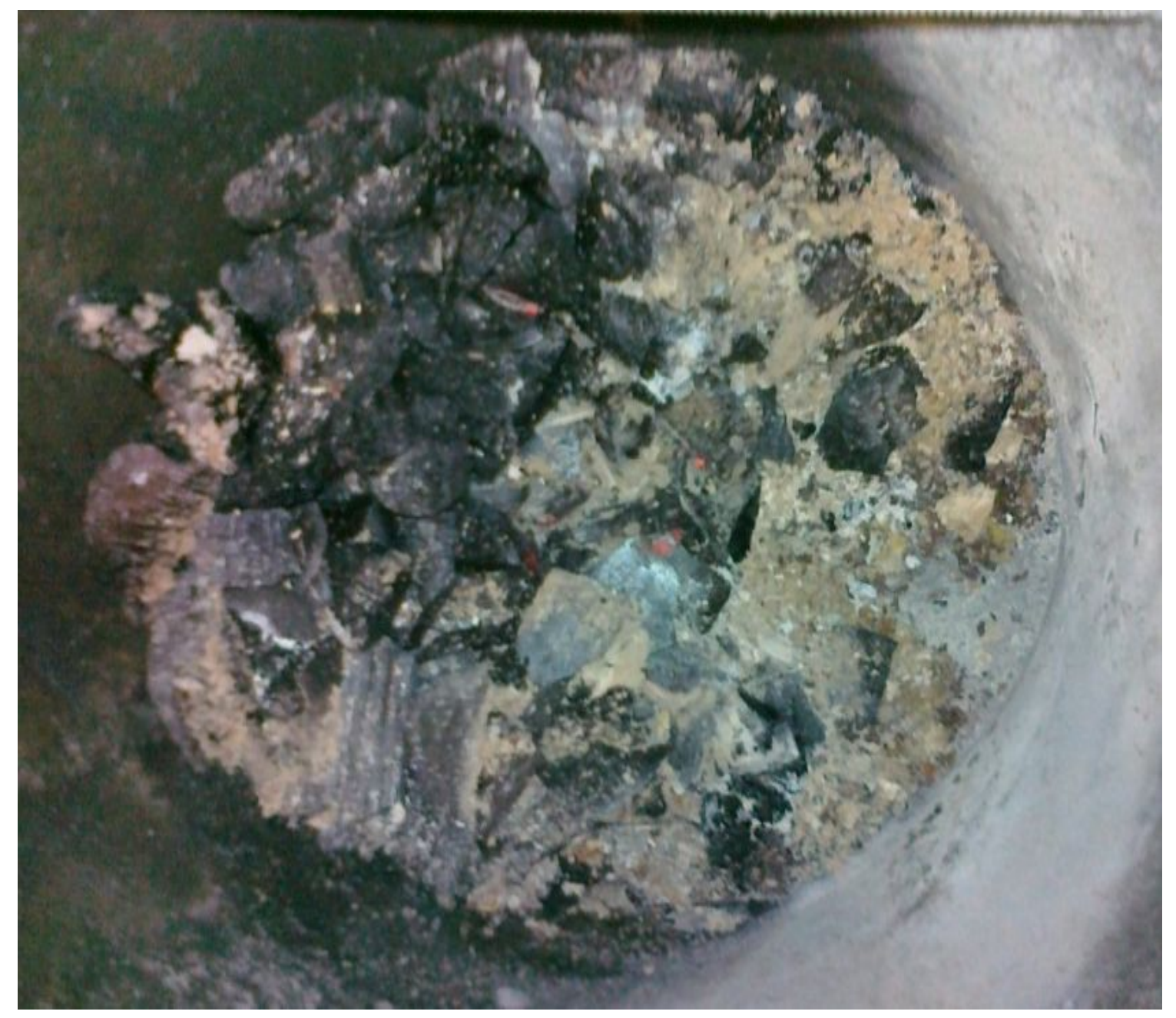

Fig. 9. Unsuccessful attempt of tar reduction with biochar bed. 


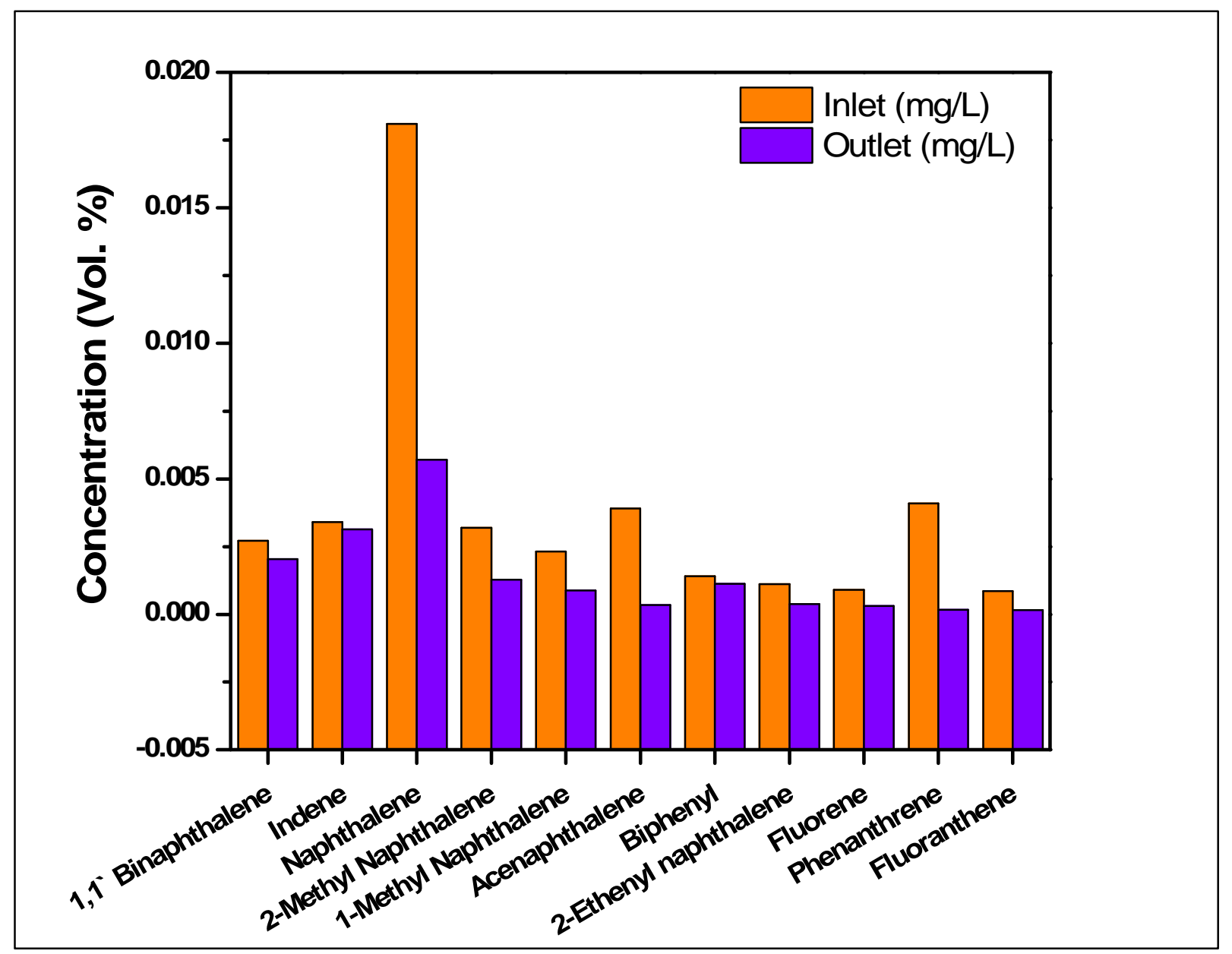

Fig. 10. Tar component concentration at inlet and outlet without water spray based mop fan. 


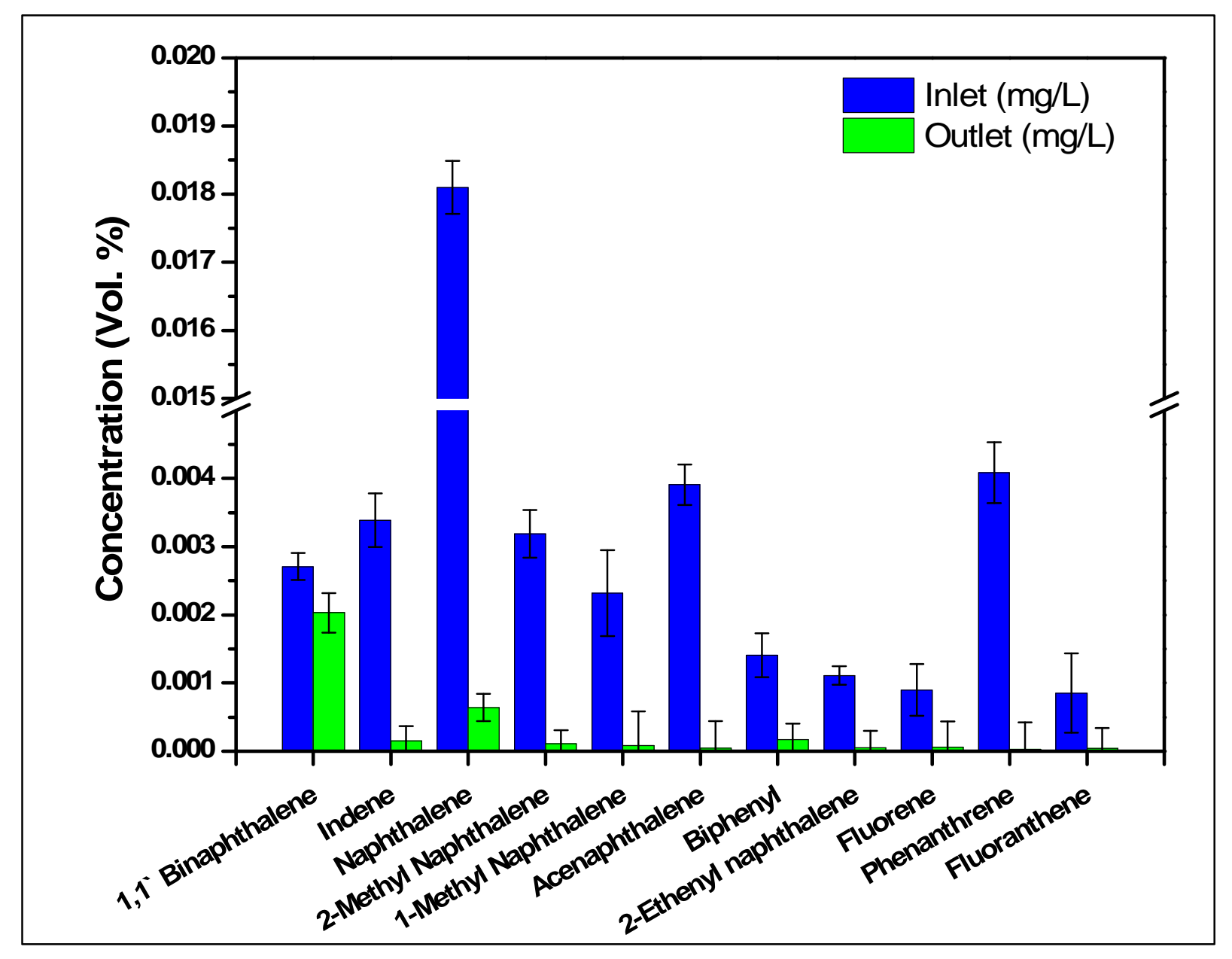

Fig. 11. Tar component concentration at inlet and outlet with water spray based mop fan. 


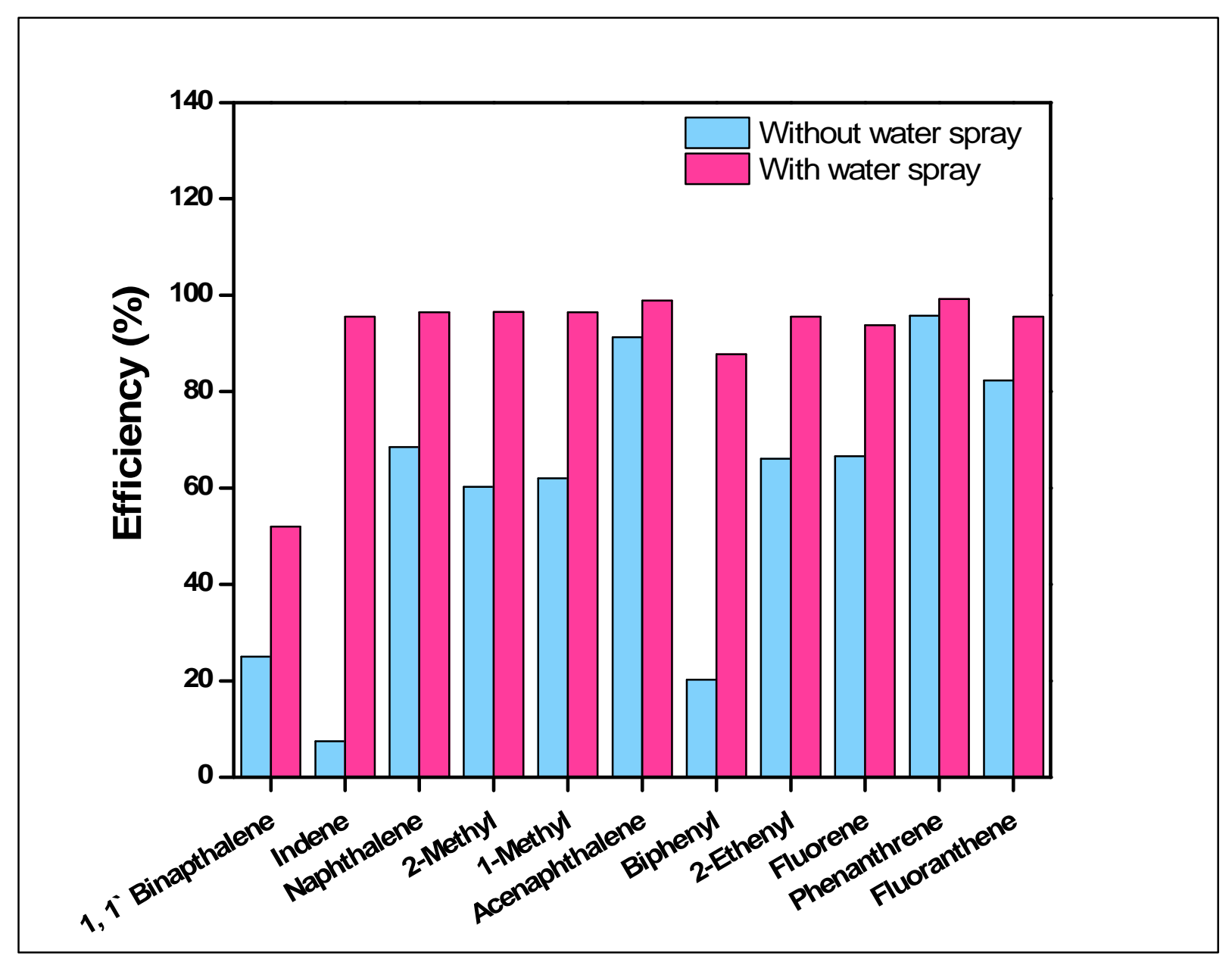

Fig. 12. Comparison of tar component capture efficiency using mop fan with or without water spray. 


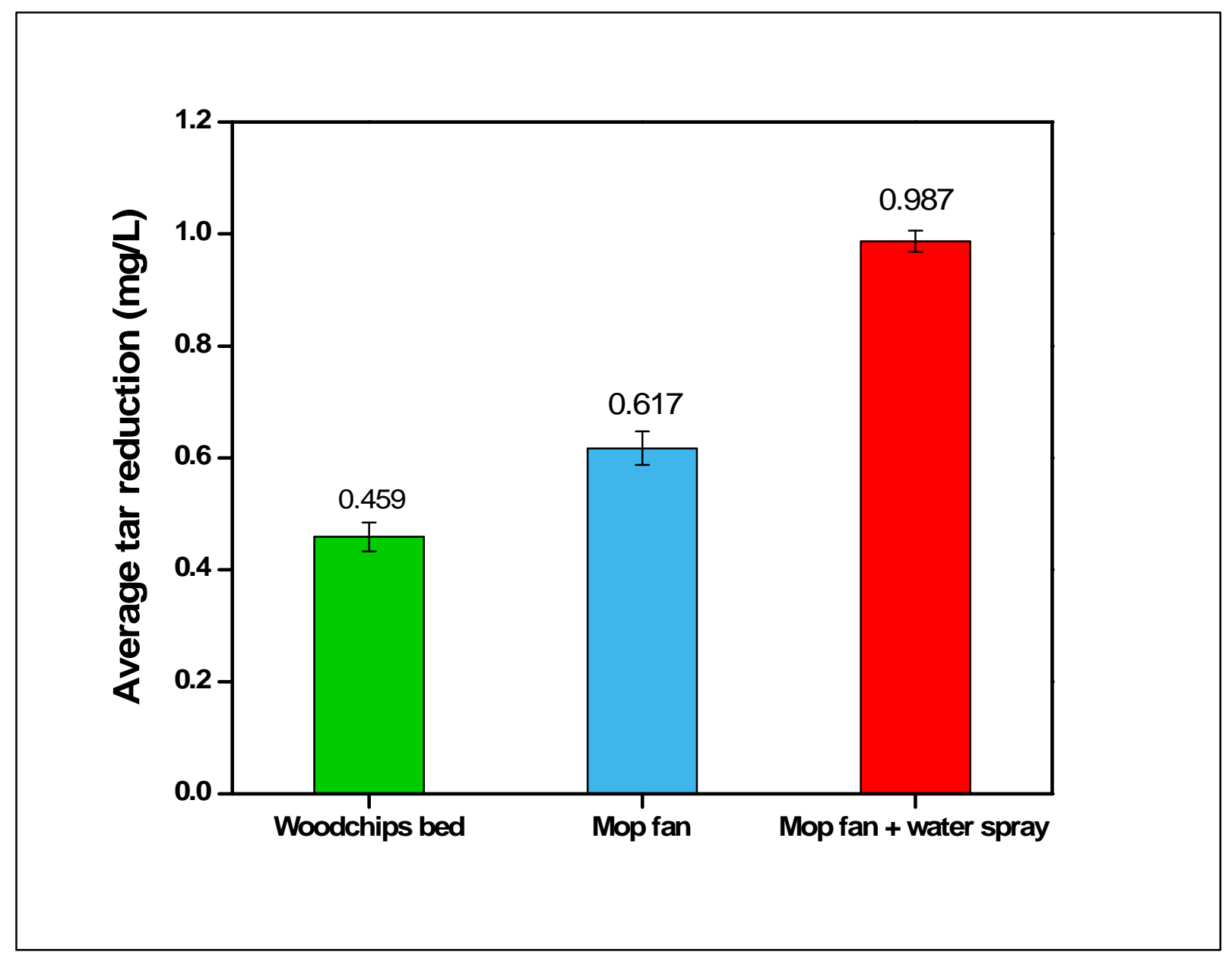

Fig. 13. Comparison of different tar arrest techniques in total tar capture at $1920.6 \mathrm{~g} / \mathrm{h}$ feeding rates. 